\title{
Water Vapor Sorption on the Surface of Selected Organic Samples in an Artificial Static Magnetic Field of $10 \mathrm{mT}$
}

\author{
Aneta Ocieczek ${ }^{1 *}$, Zbigniew Otremba ${ }^{2}$ \\ ${ }^{1}$ Gdynia Maritime University, Faculty of Entrepreneurship and Quality Science, Department of Commodity \\ Science and Quality Management, Morska Street, 81-87, 81-225 Gdynia, Poland \\ ${ }^{2}$ Gdynia Maritime University, Faculty of Marine Engineering, Department of Physics, Morska Street, 81 - \\ 87, 81-225 Gdynia, Poland
}

\begin{abstract}
This paper presents one of the aspects of a wide range of challenges related to space exploration. The main factor making it possible for humans to engage in space exploration is the provision of a basic element of existence, which is stable quality food. The starting point for the conducted research was the assumption that surface phenomena, involving water and determining food stability, can occur with different intensities under extra-terrestrial conditions. The results of this study describe the effect of the $10 \mathrm{mT}$ static magnetic field on the process of water vapor particle adsorption and desorption on the surface of organic samples. The research material included powders with hygroscopic properties: gelatin (protein) and starch (carbohydrates). The research included a comparison of the direction, dynamics, and range of water vapor sorption in control conditions in a homogenous, static magnetic field. The research involved the use of desiccators with aqueous saturated solutions of $\mathrm{NaOH}$ and $\mathrm{NaCl}$, and a static magnetic field generator. The obtained results indicate that magnetic field has an effect on the course of sorption on organic samples, and it can determine food stability during storage. The results of this work also indicate that there is the potential for reducing the costs of food preservation by drying it in the presence of a magnetic field; the study introduces innovative solutions in the construction of cereal silos, which is part of the concept of sustainable development.
\end{abstract}

Keywords: Range and dynamics of sorption; Sorption properties of food; Space exploration; Static magnetic field

\section{Introduction}

In the context of the results of many research studies (Ruiz Celma et al., 2012; Ocieczek, 2014; Mishra et al., 2016) on the durability of dehydrated foods, a question has arisen as to whether a magnetic field (Zubaidah et al., 2014) has any impact on the surface phenomena occurring in organic matter that could potentially determine its storage stability.

The phenomenon of water vapor sorption on the surface of organic samples, e.g., food products, can occur with various kinetics, depending on their properties as determined by their chemical composition and physical structures, on the difference between the water activity in the sample and the relative pressure of the surrounding air, and on the nature 
of the phenomenon taking the form of adsorption or desorption (Gondek and Lewicki, 2007; Huespe et al., 2017).

Studies on the kinetics (including the direction and the dynamics) of water vapor sorption in selected food products have demonstrated that the effect of the relative moisture of the atmosphere on sorption depends on the physical and chemical properties of the product. Starch is a natural substance with a relatively high homogeneity (Judawisastra et al., 2018) and high kinetics of sorption, which is determined by a significant number of sorption centers with a balanced energy level. Sorption does not reveal the change in the mechanism in the course of sorption under the impact of water vapor in the surrounding atmosphere (Ocieczek, 2013). However, changes in the sorption mechanism of amorphous products is a concern, and they are most often related to structural changes in the components of the products, which may include swelling, the increased mobility of protein chains, or the exposure of new sorption centers. Such changes are typical of powdered gelatin, which has a partially crystalline polymer with a lower degree of order in comparison to starch granules. Gelatin is subject to structural changes under the effect of water, even swelling in contact with cold water (Park et al., 2008). As a result of the structural transformations of the component, the rate of sorption is either constantly maintained at a high level or periodically increases, since sorption includes an increasing number of active centers available for water particles. Additionally, after absorbing a certain amount of water, specific for the given substance, the amorphous components can transform into a crystalline form (Pałacha and Sitkiewicz, 2010), which, for average values of relative humidity of the atmosphere, can only absorb and maintain small amounts of water. The change of an amorphous component into a crystalline form triggers a change in the sorption mechanism.

Previous studies have demonstrated the effects of magnetic field on various types of biological and physicochemical processes, which were particularly applied in environmental engineering, e.g., in the crystallization of calcium carbonate (Fathi et al., 2006), water treatment (Ambashta and Sillanpää, 2010), the coagulation and sedimentation of colloid particles (Higashitani, 1996), and sewage treatment (Ji et al., 2010; Zhang et al., 2011). Moreover, research findings have indicated that the magnetic field has an effect on the dynamics of some of the reactions that occur in food during its storage (Kędzierska-Matysek et al., 2018) as well as on the proper functioning of living organisms (Fey et al., 2019; Stankevičiūtè et al., 2019; Jakubowska et al., 2019).

The only work addressing the issue of the effect of a magnetic field on the course of surface phenomena was a study by Ocieczek and Otremba (2019) on the effect of a magnetic field on the course of water desorption from the surface of starch granules. However, the effects of the magnetic field on the course of surface phenomena in a wider range of water activities have not been examined yet. Therefore, the study discussed in this paper aimed to evaluate the effect of a static magnetic field on the intensity (which involves direction, dynamics, and range) of the surface phenomena, expressed by the adsorption or desorption of water vapor by the matrix of the solid substance (organic sample). The results were used to verify the assumption concerning the existence of a significant effect of static magnetic field on the intensity of the sorption process that occurs on the surface of organic samples demonstrating hygroscopic properties. It was hypothesized that the effect of the magnetic field changes the thermodynamic status of the water particles remaining in the environment and in the organic samples under examination. Consequently, the natural phenomena related to the movement of water molecules in order to reach dynamic equilibrium with the environment, as demonstrated by maximum disorder and minimum energy, can occur with different intensities. 


\section{Methods}

Two substances were used as the research material: gluten-free wheat starch, industrially manufactured by Wytwórnia Artykułów Bezglutenowych BEZGLUTEN s.c. (Koniusza near Cracow, Poland), and pork gelatin, manufactured by FoodCare Sp. z o.o. (Zabierzów, Poland). Both samples were in the form of fine powders.

The water content in the examined material was determined by drying at $105^{\circ} \mathrm{C}$ to a solid mass. The assay was carried out in three parallel replications.

Water activity $\left(\mathrm{a}_{\mathrm{w}}\right)$ at $20^{\circ} \mathrm{C}$ was determined with an accuracy of \pm 0.003 in the AquaLab apparatus (ver. AS4 2,14.0 2017, Series 4TE and 4TEV Decagon Devices, Inc., Pullman, WA, USA).

In this experiment, the time required to reach the state of dynamic equilibrium was assumed based on the research results reported by Ocieczek et al. (2015). This time was extended, assuming that the rate of reaching dynamic equilibrium may be different, depending on the properties of the sorbents used in the experiment.

The kinetics of water vapor sorption was determined based on the direction and rate of the changes in the weight of the examined samples, as determined by changes in their water content. The research material included approximately $1 \mathrm{~g}$ samples each of starch and gelatin. The average water content was $13.901 \mathrm{~g} \mathrm{H}_{2} \mathrm{O} / 100 \mathrm{~g}$ d.m. with a standard deviation of $0.257 \mathrm{~g} \mathrm{H}_{2} \mathrm{O} / 100 \mathrm{~g}$ d.m. in the starch and11.436 $\mathrm{g} \mathrm{H}_{2} \mathrm{O} / 100 \mathrm{~g} \mathrm{~d} . \mathrm{m} . \pm 0.240 \mathrm{~g}$ $\mathrm{H}_{2} \mathrm{O} / 100 \mathrm{~g}$ d.m. in the gelatin. The average water activity was $0.4615 \pm 0.0064$ and 0.3016 \pm 0.0020 , for the starch and gelatin, respectively. The examined samples were collected directly from the package that was hermetically sealed by the manufacturer.

The samples were placed in desiccators in environments with water activity of $0.0891 \pm 0.024$ regulated by saturated solution of $\mathrm{NaOH}$ and $0.7547 \pm 0.0014$ regulated by saturated solution of $\mathrm{NaCl}$ (Figura and Teixeira, 2007). Measurements of the weight of the examined samples were carried out each time after the end of their exposure to the environment (after 1, 3, 6, and 8 days). The measurements were conducted in a thermostat at $20^{\circ} \mathrm{C} \pm 1{ }^{\circ} \mathrm{C}$.

Twelve sets of samples were prepared in glass bottles with ground glass lids-six containing starch and six containing gelatin. Half of the samples were placed in desiccators located in a $10 \mathrm{mT}$ uniform static magnetic field. The second half of the samples were placed in the same desiccators, but far from the generator coils (Figure 1).

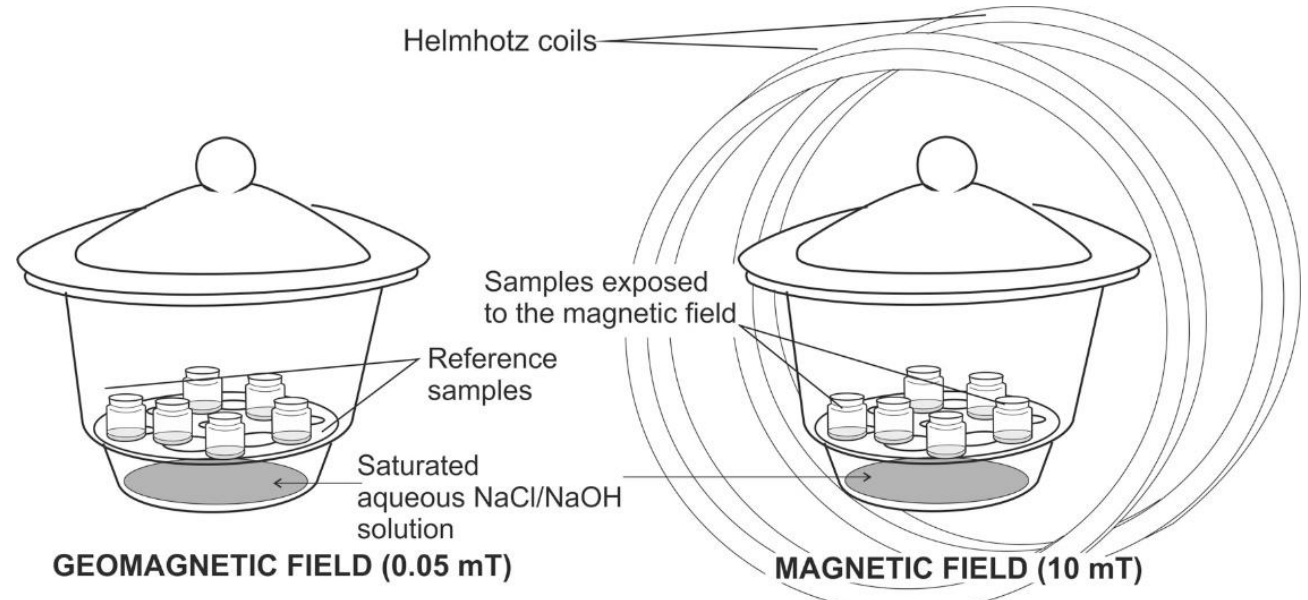

Figure 1 Experimental setup: Desiccator with reference samples in the geomagnetic field of 0.05 $\mathrm{mT}$ (left), desiccator between the Helmholtz coils-generated static uniform magnetic field of $10 \mathrm{mT}$ (right) 
The static magnetic field generator was designed and constructed at the Physics Department of Gdynia Maritime University. It consists of two identical Helmholtz coils arranged parallel to each other. The electric current in the coils (14 amps) required to generate an even magnetic field of $10 \mathrm{mT}$ is provided by two laboratory switching mode power supplies HCS-3602 (Manson Technology, Beijing, China). The heat from the coils is discharged by circulating water through the flow cooler (Titan 4000, Aqua Medic GmbH, Bissendorf, Germany). The generator is equipped with an AC gaussmeter GM-2 (AlphaLab, Inc., Salt Lake City, USA) that measures and adjusts the value of magnetic induction.

The significance of the differences between the average water content values in the examined samples after their incubation under the control conditions and the static magnetic field conditions at the same time intervals were assessed with using a Student's t-test. Fisher's test was used to evaluate the variability (variation assessment) in the compared groups.

\section{Results and Discussion}

The first stage of the experiment involved measurement of changes in the weights of the samples placed in the desiccator containing a saturated solution of $\mathrm{NaCl}$. Dehydrated samples of the solids, featuring an affinity for water (hygroscopic), remain in the atmosphere where water vapor is present, react with it on the surface until dynamic equilibrium is achieved (Ocieczek and Otremba, 2019). In this status, at the specified time interval, the same number of particles of the adsorbate (water) are subject to adsorption and desorption on the surface of the adsorbent. As a result of the system moving towards achieving dynamic equilibrium, the rate of the dynamic mass change moves towards zero (Figure 2 and Figure 3).

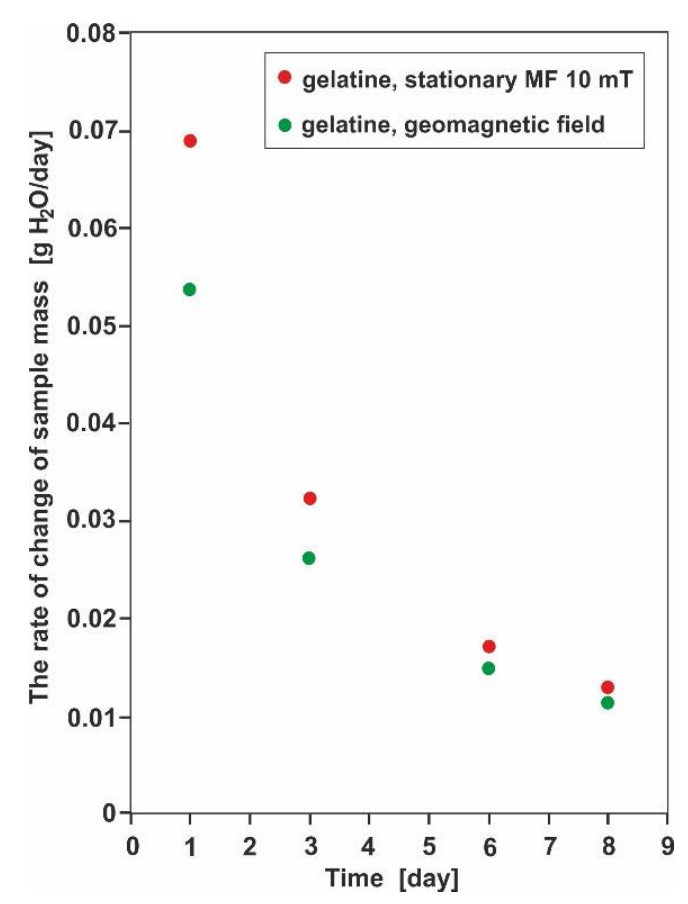

Figure 2 Rate of the changes in the weight of the gelatin sample by adsorption of water vapor regulated by the saturated $\mathrm{NaCl}$ solution $(75 \%)$ in ordinary conditions and under the effect of an artificial static magnetic field

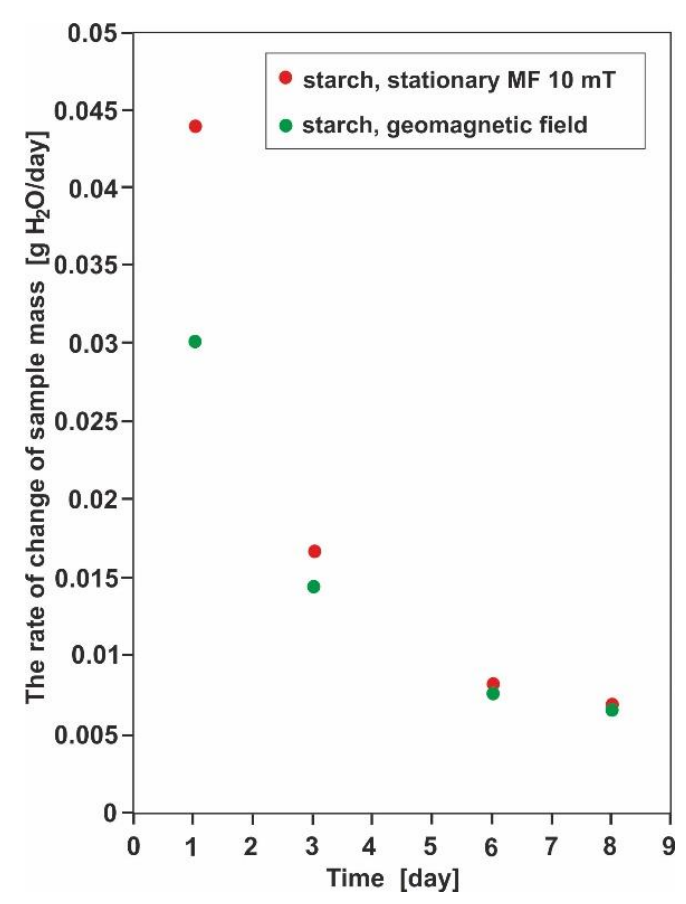

Figure 3 Rate of the changes in the weight of the gluten-free starch sample by adsorption of water vapor regulated by the saturated $\mathrm{NaCl}$ solution $(75 \%)$ in ordinary conditions and under the effect of an artificial static magnetic field 
The examined phenomenon consisted of the adsorption of water vapor particles on the surface of the gelatin (protein) and starch (carbohydrate) samples, producing a dynamic equilibrium, featuring minimum energy and maximum disorder. This was accompanied by an increase in the weights of the examined samples to the level typical for those samples (Figure 4 and Figure 5).

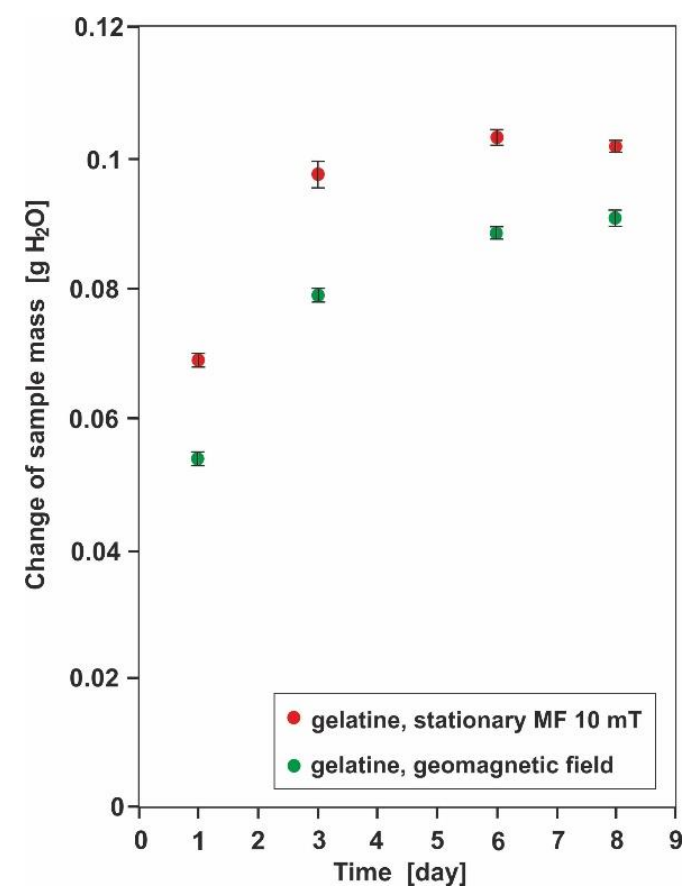

Figure 4 Changes in the weight of the gelatin sample by adsorption of water vapor regulated by the saturated $\mathrm{NaCl}$ solution $(75 \%)$ in ordinary conditions and under the effect of an artificial static magnetic field

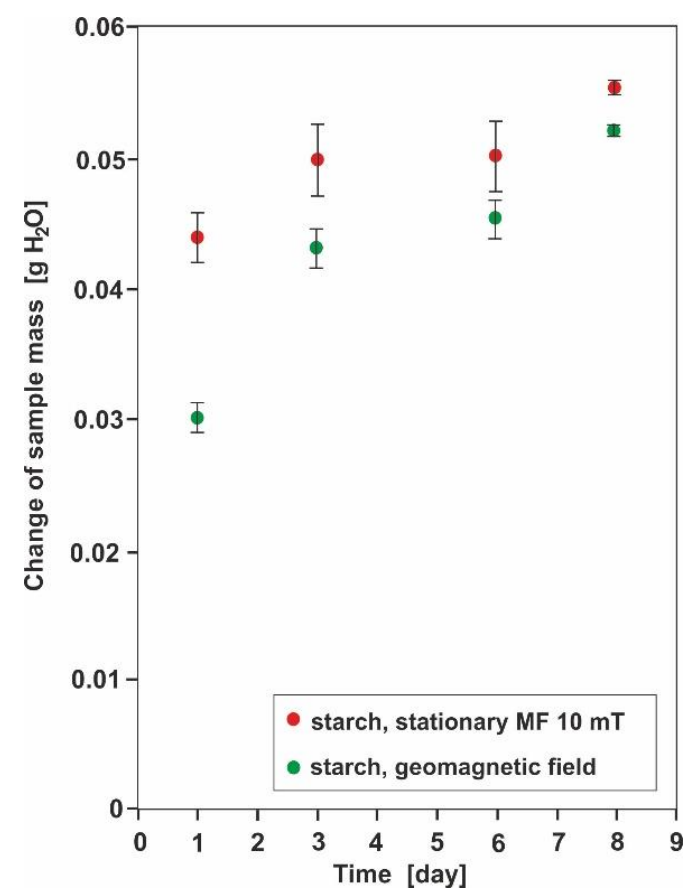

Figure 5 Changes in the weight of the glutenfree starch sample by adsorption of water vapor regulated by the saturated $\mathrm{NaCl}$ solution $(75 \%)$ in ordinary conditions and under the effect of an artificial static magnetic field

At the same time, the experiment demonstrated that the samples stored in the desiccator containing a saturated solution of $\mathrm{NaCl}$ and exposed to the $10 \mathrm{mT}$ static magnetic field, aiming towards dynamic equilibrium, absorbed (in the same time units) statistically significantly $(0.001<\mathrm{P}<0.05)$ higher amounts of water from the environment than the samples stored in the desiccator containing a saturated solution of $\mathrm{NaCl}$ under the control conditions (Table 1).

Table 1 Statistical evaluation of the differences between the average changes in the weight of the samples stored in a geomagnetic field of $0.05 \mathrm{mT}$ and in an artificial magnetic field of $10 \mathrm{mT}$ under temperature- and humidity-controlled conditions $\left(20^{\circ} \mathrm{C}, 75 \%\right)$

\begin{tabular}{lcccc}
\hline \multirow{2}{*}{ Statistical value } & 1 & 3 & Time (days) & 6 \\
& \multicolumn{5}{c}{ gelatine } \\
\cline { 2 - 5 } & 0.1230 & 0.1535 & 0.2248 & 0.7176 \\
Test $F$ & $2.5917 \mathrm{E}-05$ & $7.9786 \mathrm{E}-05$ & $2.9444 \mathrm{E}-05$ & 0.0001 \\
\hline P-value & 0.6038 & 0.4573 & starch & 0.5240 \\
\hline Test $\mathrm{F}$ & 0.0004 & 0.0199 & 0.0508 & 0.4717 \\
P-value & &
\end{tabular}


The placement of the samples in the desiccator induced an exothermic desorption process on their surface. Probably under the effect of the static magnetic field, the pressure of the vapor in the desiccator increased. This, in turn, resulted in establishing a new dynamic equilibrium status, the effect of which was higher adsorption of water vapor by the examined samples and a greater increase in their weight in comparison to the samples that remained in the control conditions. Therefore, it was hypothesized that, under the effect of a static magnetic field, the thermodynamic status of water particles changes, and they evaporate. In this type of system, the presence of a magnetic field favored increased entropy. Consequently, it can be claimed that a static magnetic field affects the intensity of the surface phenomena, although this effect does not seem to be thermal.

The measurements showed that the increases in the weights of the examined samples were significantly $(0.001<\mathrm{P}<0.05)$ lower for the samples stored under control conditions than the samples stored under conditions of a static magnetic field. Thus, the static magnetic field resulted in the performance of more work in comparison to the work performed in the absence of the magnetic field impact (Bolton, 1982; Feynman et al., 1974). After the experiment, the examined systems were in states other than the states they were in before the work was done, as determined by changes in the weight of the samples and the saturated salt solutions (Ocieczek, 2013; Ocieczek et al., 2015; Ocieczek and Otremba, 2019).

The work performed describes energy, the source of which could be the magnetic field (Ocieczek and Otremba, 2019). Following this reasoning, it could be claimed that the energy related to the static magnetic field caused an increase in water vapor pressure above the saturated $\mathrm{NaCl}$ solution. In turn, this energy broke the hydrogen bonds binding the water molecules in the form of liquid, resulting in vaporization of its particles. Simultaneously, this could be the source of the higher values of the energy of the water vapor particles. Therefore, it can be assumed that the static magnetic field stimulates a system (a saturated solution-a sample) towards entropy in the process of adsorption occurring on the surface of the examined samples.

The second stage of the experiment included, by analogy to the first state, an examination of the changes in the weights of the samples remaining in the desiccator containing the saturated $\mathrm{NaOH}$ solution. The observed phenomenon consisted of desorption of the water particles from the area of the examined samples of gelatin (protein) and starch (carbohydrates) (Ocieczek and Otremba, 2019). As a consequence of the system striving to reach the state of dynamic equilibrium, the rate of the weight changes in the examined samples systematically decreased towards zero (Figure 6 and Figure 7); thus, no changes in the adsorbent weight over time were observed (Figure 8 and Figure 9).

Moreover, it was found that the samples stored in the desiccator placed in the magnetic field, in order to reach a state of dynamic equilibrium with the environment, released (in the same time units) amounts of water that were not statistically different $(\mathrm{P}<0.05)$ from the amounts of water released by the samples stored in the control conditions (Table 2 ). 


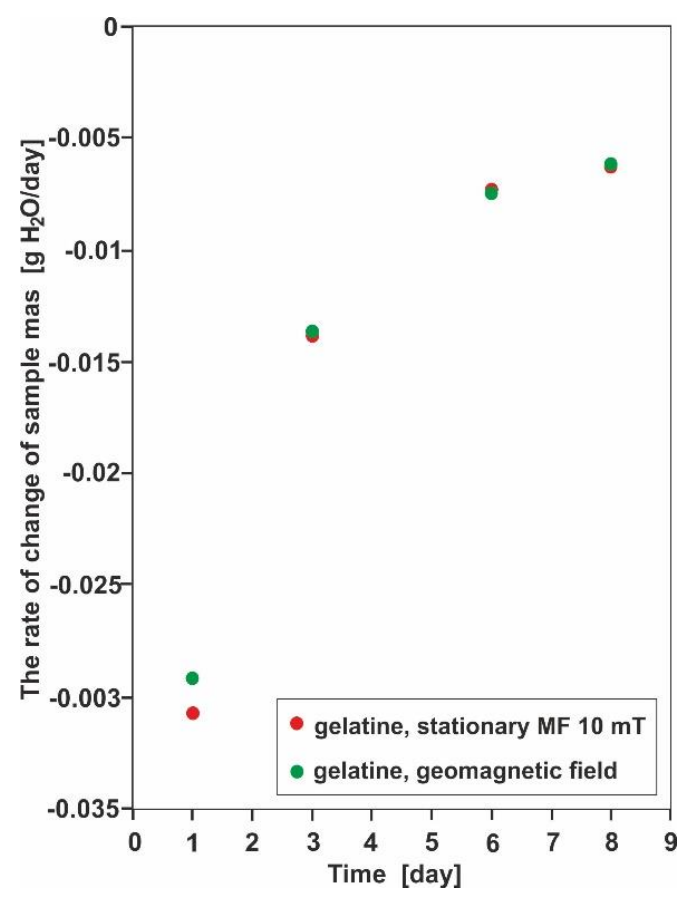

Figure 6 Rate of the changes to the weight of the gelatin samples by desorption of water vapor regulated by the saturated $\mathrm{NaOH}(8.9 \%)$ solution in ordinary conditions and under the effect of an artificial static magnetic field

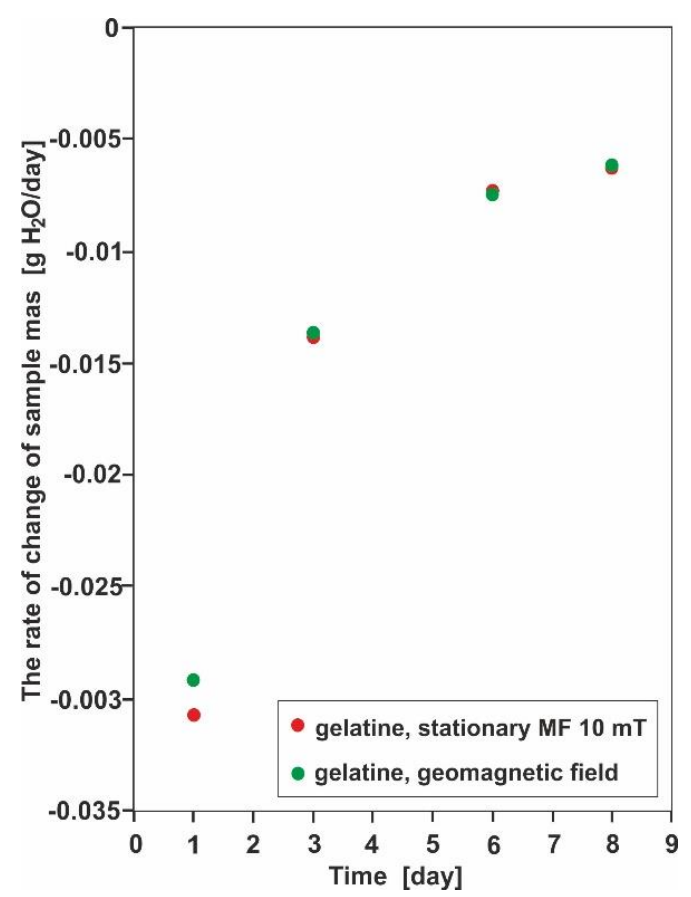

Figure 8 Changes to the weight of the gelatin samples by desorption of water vapor pressure regulated by the saturated $\mathrm{NaOH}$ solution $(8.9 \%)$ in ordinary conditions and under the effect of an artificial static magnetic field

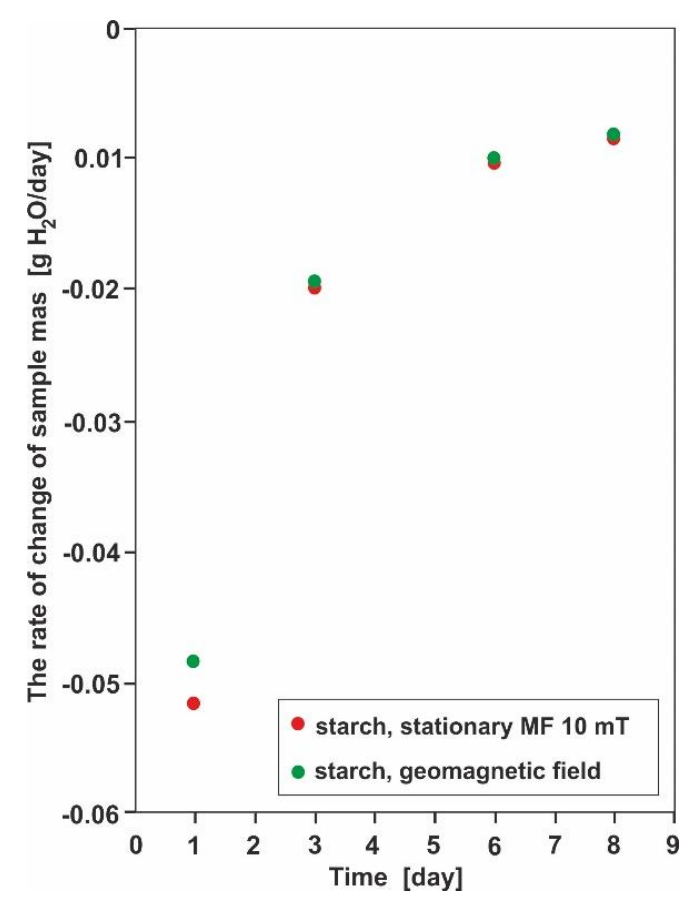

Figure 7 Rate of the changes to the weight of the gluten-free starch samples by water desorption of water vapor regulated by the saturated $\mathrm{NaOH}(8.9 \%)$ solution in ordinary conditions and under the effect of an artificial static magnetic field

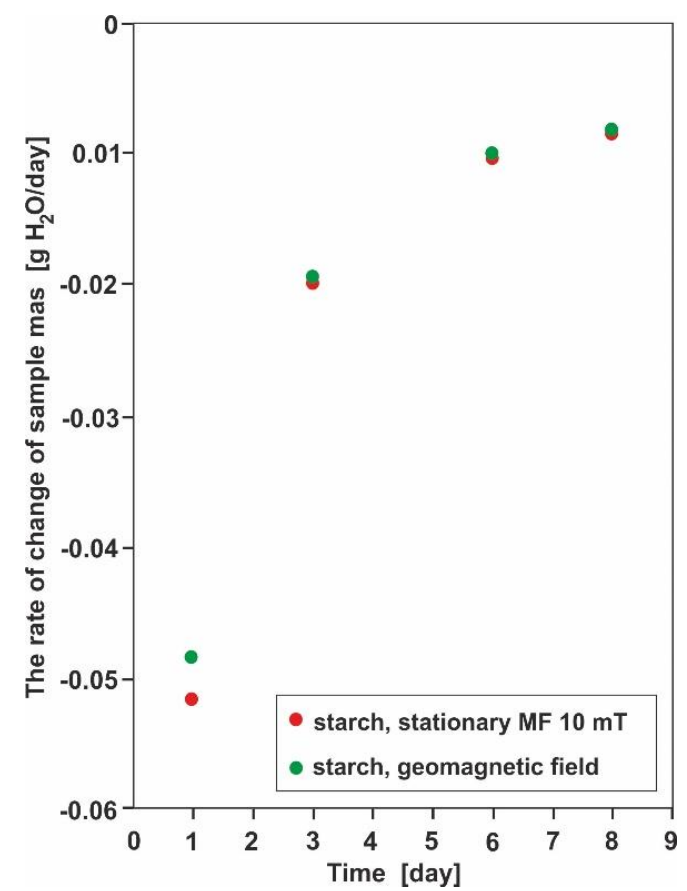

Figure 9 Changes in the weight of the glutenfree starch samples by desorption of water vapor regulated by the saturated $\mathrm{NaOH}(8.9 \%)$ solution in ordinary conditions and under the effect of an artificial static magnetic field 
Table 2 Statistical evaluation of the differences between the average changes in the weight of samples stored in the geomagnetic field of $0.05 \mathrm{mT}$ and in the artificial magnetic field of $10 \mathrm{mT}$ under temperature- and humidity-controlled conditions $\left(20^{\circ} \mathrm{C}, 8.9 \%\right)$.

\begin{tabular}{|c|c|c|c|c|}
\hline \multirow{3}{*}{ Statistical value } & \multicolumn{4}{|c|}{ Time (days) } \\
\hline & 1 & 3 & 6 & 8 \\
\hline & \multicolumn{4}{|c|}{ gelatine } \\
\hline Test $\mathrm{F}$ & 0.1 & 0.0964 & 0.7273 & 0.7273 \\
\hline \multirow[t]{2}{*}{$\mathrm{P}$-value } & 0.0191 & 1 & 0.0217 & 0.1447 \\
\hline & \multicolumn{4}{|c|}{ starch } \\
\hline Test F & 0.5332 & 0.2923 & 0.9703 & 0.3250 \\
\hline P-value & 0.0267 & 0.6836 & 0.3352 & 0.1301 \\
\hline
\end{tabular}

Placing the samples in the desiccator induced an endothermic desorption process on their surface. By analogy to the first stage of the research, it was hypothesized that, under the effect of the magnetic field, the dynamics of the system would increase when it is striving towards increasing entropy, the consequence of which was strong adsorption of the water molecules by a solution of $\mathrm{NaOH}$. A more intensive adsorption under the effect of the magnetic field resulted in the local release of heat, which, according to the contradiction rule, inhibited further adsorption (Figura and Teixeira, 2007; Ocieczek and Otremba, 2019). Since the effect of the static magnetic field on the system initiated two phenomena that occurred in parallel, but in opposite directions, it was assumed that the vapor pressure in the desiccator probably did not significantly change in an observable way.

It has been empirically proven that the desorption of water vapor from the surface of the examined samples stored in control conditions and stimulated with the static magnetic field progresses with the same dynamics and within the same range.

The final step of the research consisted of a comparison of the sorption range in the control conditions and when stimulated with a static magnetic field. Differences in the equilibrium state were determined by comparing the water content in the examined samples after eight days of storage, which was assumed as a satisfactory period for reaching a state of dynamic equilibrium by this system (Ocieczek et al., 2015). A statistical evaluation of the differences demonstrated that the range of adsorption, expressed as an increase in the weight of the samples after eight days of storage, was higher in the magnetic field condition $\left(\mathrm{t}_{\mathrm{GC} / \mathrm{GF} / \mathrm{NaCl}}=14.0608 ; \mathrm{t}_{\mathrm{SC} / \mathrm{SF} / \mathrm{NaCl}}=12.311 ; \mathrm{t}_{0,001}=8.61\right)$. In turn, the range of desorption under the effect of the field was not significantly statistically different in the magnetic field condition $\left(\mathrm{t}_{\mathrm{GC} / \mathrm{GF} / \mathrm{NaOH}}=0.671 ; \mathrm{t}_{\mathrm{SC} / \mathrm{SF} / \mathrm{NaOH}}=3.113 ; \mathrm{t}_{0,05}=2.776\right)$.

The range of the sorption process is reflected in the static description of this phenomenon, namely, the sorption isotherm (Figura and Teixeira, 2007; Gondek and Lewicki, 2007; Ocieczek et al., 2015). However, each point at the sorption isotherm is reached as a result of a dynamic process with different specificity, related to more or less complex mechanisms, which lead to achieving the status of dynamic equilibrium (Huespe et al., 2017). The described sorption rate variability over time in different environmental conditions is consistent with the multilayer adsorption theory and the capillary condensation theory. Even with small coverage of the adsorbent surface with water particles (the first stage of sorption at the sorption isotherm), the intermolecular reactions of the water-matrix determine the energy status of the adsorbent surface, and the sorption process is dynamic. However, each adsorbed water particle changes the sorption conditions. After filling all available active centers (although with various energy values) the intermolecular reactions become homogenous and were, mainly, represented by the water-water reactions (the second stage of sorption at the sorption isotherm). Thus, to a 
small degree, the sorption rate becomes dependent on the differences in the pressure of the water vapor in the examined sample and its environment. A further process of adsorption leads to filling some of the capillaries (i.e., capillary condensation). At this stage of the adsorption process, the average sorption rate for the entire material sorption rate on the surface of amorphous bodies again becomes dependent on the intermolecular relations of the water-matrix due to emerging structural changes. The relation between the sorption rate and the sorption stage makes it possible to determine the capacity of the monolayer and the water content initiating capillary condensation in the material, based on the sorption isotherms, which are diagrams describing the statics of this phenomenon.

In summary, it should be stated that the presence of a magnetic field has a significant effect on the sorption properties of organic materials. This is an important reason why, in extra-terrestrial conditions with different magnetic characteristics from the Earth, food with known storage properties will have new properties. Thus, its storage stability may also be substantially different.

\section{Conclusions}

The results of the experiments demonstrate the effect of a static magnetic field on the kinetics and the range of water adsorption by powdered gelatin and starch. It was found that a static and homogenous $10 \mathrm{mT}$ magnetic field increases the rate of water adsorption by those substances, particularly in the initial phase of this process. Additionally, due to the magnetic field, the status of dynamic equilibrium between the sample and the atmosphere is established at various levels, i.e., it is higher in the magnetic field. The effect of the field can be explained by the change in the thermodynamic state of the water particles, which leads to increased water vapor pressure, resulting in either an increase in entropy or stimulation of the substances' ability to adsorb water, which should also be treated as a factor favoring an increase in entropy.

The water desorption of those substances is similar in the magnetic field and in the absence of that field. However, there are no grounds to claim that the magnetic field does not participate in this process. It seems more probable that the field can exert its influence through mutually competitive kinetic processes.

The results of this work provide a starting point in research that aims to create the foundations for predicting changes in food stored under conditions, such as space exploration environments, that are different from terrestrial conditions. The results of this work also indicate that the presence of a magnetic field with an induction greater than the Earth's may contribute to the change in the dynamics of the drying process and affect the state of water in dehydrated materials, which is important from the point of view of the efficiency of the drying process and food stability during storage. This, in turn, may have great importance for the implementation of the concept of sustainable development based on an energy-efficient economy (Shakouri et al., 2018).

\section{Acknowledgements}

This work was supported by the grant No. WPiT/2019/PZ/05

\section{References}

Ambashta, R.D., Sillanpää, M., 2010. Water Purification using Magnetic Assistance: A Review. Journal of Hazardous Materials, Volume 180 (1-3), pp. 38-49

Bolton, W., 1982. Outline of Physics. PWN, Warszawa, Poland. 
Fathi, A., Mohamed, T., Claude, G., Maurin, G., Mohamed, B.A., 2006. Effect of a Magnetic Water Treatment on Homogeneous and Heterogeneous Precipitation of Calcium Carbonate. Water Research, Volume 40(10), pp. 1941-1950

Fey, D.P., Greszkiewicz, M., Otremba, Z., Andrulewicz, E., 2019. Effect of Static Magnetic Field on the Hatching Success, Growth, Mortality, and Yolk-sac Absorption of Larval Northern Pike Esox lucius. Science of the Total Environment, Volume 647, pp. 12391244

Feynman, R.P., Leighton, R.B., Sands, M., 1974. Feynman Lectures in Physics. Volume 1, Part 2. PWN, Warszawa, Poland.

Figura, L.O., Teixeira, A.A., 2007. Food Physics. Physical Properties-Measurement and Applications. Springer Press, Heidelberg, Germany

Gondek, E., Lewicki, P.P., 2007. Kinetics of Water Vapour Sorption by Selected Ingredients of Muesli-type Mixtures. Polish Journal of Food and Nutrition Sciences, Volume 57(3A), pp. 23-26

Higashitani, K., 1996. Effects of Magnetic Field on Stability of Non-magnetic Colloidal Particles. In: Proceedings of the $2^{\text {nd }}$ International Meeting on Anti-Scale Magnetic Treatment. Cranfield University, United Kingdom

Huespe, V.J., Belardinelli, R.E., Pereyra, V.D., Manzi, S.J., 2017. Comparison between Different Adsorption-desorption Kinetics Schemes in Two-dimensional Lattice Gas. Physica A: Statistical Mechanics and its Applications, Volume 488, pp. 162-176

Jakubowska, M., Urban-Malinga, B., Otremba, Z., Andrulewicz, E., 2019. Effect of Low Frequency Electromagnetic Field on the Behavior and Bioenergetics of the Polychaete Hediste Diversicolor. Marine Environmental Research, Volume 150, p.104766

Ji, Y., Wang, Y., Sun, J., Yan, T., Li, J., Zhao, T., Yin, X., Sun, C., 2010. Enhancement of Biological Treatment of Wastewater by Magnetic Field. Bioresource Technology, Volume 101, pp. 8535-8540

Judawisastra, H., Sitohand, R.D., Taufig, D.I., Mardiyati, 2018. The Fabrication of Yam Bean (Pachyrizous erosus) Starch based Bioplastics. International Journal of Technology, Volume 9(2), pp. 345-352

Kędzierska-Matysek, M., Matwijczuk, A., Florek, M., Kornarzyński, K., Matwijczuk, A., Wolanciuk, A., Barłowska, J., Gładyszewska, B., 2018. Effect of Magnetic Field on 5hydroxymethylfurfural Content, Diastase Activity and Changes in the ATR-FTIR Spectra in Raw Buckwheat Honey. Przemysł Chemiczny, Volume 97(3), pp. 381-385

Mishra, P.K., Mishra, V.K., Maurya, V.K., Chaurasiya, J., Sahay, S., Mauriya, A.K., Tyagi, S., 2016. Evaluation of Packaging Containers for Storage of Osmo-dehydrated Product of Mango. Ecology, Environment and Conservation, Volume 22(2), pp. 635-640

Ocieczek, A., 2013. Impact of Comminution on Adsorption Properties of Gluten-free Wheat Starch. Acta Agrophysica PAN, Volume 20(1), pp. 125-136

Ocieczek, A., 2014. Comparison of the Sorption Properties of Milk Powder with Lactose and without Lactose. Acta Agrophysica PAN, Volume 21(4), pp. 457-467

Ocieczek, A., Kostek, R., Ruszkowska, M., 2015. Kinetic Model of Water Vapour Adsorption by Gluten-free Starch. International Agrophysics, Volume 29(1), pp. 115-119

Ocieczek, A., Otremba, Z., 2019. Effect of a Magnetic Field on Water Desorption from Potato Starch. Acta Agrophysica PAN, Volume 26(3), pp. 43-55

Pałacha, Z., Sitkiewicz, I., 2010. Physical Properties of Food. WNT, Warszawa, pp. 149-150

Park, J.W., Whiteside, W.S., Cho, A.Y., 2008. Mechanical and Water Vapor Barrier Properties of Extruded and Heat-pressed Gelatin Films. LWT - Food Science and Technology, Volume 41(4), pp. 692-700 
Ruiz Celma, A., Cuadros, F., López-Rodríguez, F., 2012. Characterization of Pellets from Industrial Tomato Residues. Food and Bioproducts Processing, Volume 90(4), pp. 700706

Shakouri, M., Krishnan, E.N., Dehabadi, L., Karoyo, A.H., Simonson, C.J., Wilson, L., 2018. Vapor Adsorption Transient Test Facility for Dehumidification and Desorption Studies. International Journal of Technology, Volume 9(6), pp. 1092-1102

Stankevičiūtė, M., Jakubowska, M., Pažusienė, J., Makarasa, T., Otremba, Z., Urban-Malinga, B., Fey, D.P., Greszkiewicz, M., Sauliutė, G., Baršienė, J., Andrulewicz, E., 2019. Genotoxic and Cytotoxic Effects of $50 \mathrm{~Hz} 1 \mathrm{mT}$ Electromagnetic Field on Larval Rainbow Trout (Oncorhynchus mykiss), Baltic Clam (Limecola balthica) and Common Ragworm (Hediste diversicolor). Aquatic Toxicology., Volume 208, pp. 109-117

Zhang, H., Zhao, Z., Xu, X., Li, L., 2011. Study on Industrial Wastewater Treatment using Superconducting Magnetic Separation. Cryogenics, Volume 51(6), pp. 225-228

Zubaidah, T., Kanata, B., Paniran, 2014. Three-dimensional Mapping of Static Magnetic Fields Over a Semi-anechoic Chamber. International Journal of Technology, Volume 5(3), pp. 209-218 